\title{
Population level mental distress in rural Ethiopia
}

\author{
Abebaw Fekadu ${ }^{1,2^{*}}$, Girmay Medhin ${ }^{3}$, Medhin Selamu', Maji Hailemariam¹, Atalay Alem¹, Tedla W Giorgis ${ }^{4}$, \\ Erica Breuer ${ }^{5}$, Crick Lund ${ }^{5}$, Martin Prince ${ }^{6}$ and Charlotte Hanlon ${ }^{1,6}$
}

\begin{abstract}
Background: As part of a situational analysis for a research programme on the integration of mental health care into primary care (Programme for Improving Mental Health Care-PRIME), we conducted a baseline study aimed at determining the broad indicators of the population level of psychosocial distress in a predominantly rural community in Ethiopia.

Methods: The study was a population-based cross-sectional survey of 1497 adults selected through a multi-stage random sampling process. Population level psychosocial distress was evaluated by estimating the magnitude of common mental disorder symptoms (CMD; depressive, anxiety and somatic symptoms reaching the level of probable clinical significance), harmful use of alcohol, suicidality and psychosocial stressors experienced by the population.

Results: The one-month prevalence of CMD at the mild, moderate and severe threshold levels was 13.8\%, 9.0\% and $5.1 \%$ respectively. The respective one-month prevalence of any suicidal ideation, persistent suicidal ideation and suicide attempt was $13.5 \%, 3.8 \%$ and $1.8 \%$. Hazardous use of alcohol was identified in $22.4 \%$, significantly higher among men (33.4\%) compared to women (11.3\%). Stressful life events were widespread, with $41.4 \%$ reporting at least one threatening life event in the preceding six months. A similar proportion reported poor social support (40.8\%). Stressful life events, increasing age, marital loss and hazardous use of alcohol were associated with CMD while stressful life events, marital loss and lower educational status, and CMD were associated with suicidality. CMD was the strongest factor associated with suicidality [e.g., OR $(95 \% \mathrm{Cl})$ for severe $\mathrm{CMD}=60.91(28.01,132.48)$ ] and the strength of association increased with increase in the severity of the CMD.
\end{abstract}

Conclusion: Indicators of psychosocial distress are prevalent in this rural community. Contrary to former assumptions in the literature, social support systems seem relatively weak and stressful life events common. Interventions geared towards modifying general risk factors and broader strategies to promote mental wellbeing are required.

Keywords: Common mental disorders, Psychosocial distress, Mental distress, Suicidality, Hazardous alcohol use, Wellbeing, Developing country, Africa South of the Sahara, Sub-Saharan Africa, Ethiopia

\section{Background}

Common mental disorders (CMD) refer to either the occurrence of a combination of non-specific anxiety, depressive and somatic symptoms [1] or anxiety, depressive and somatoform disorders "usually measured" with screening tools [2]. The exact genesis of the term is not clear but appears to have come into use with the decline in the use of the term "neurosis". The leaders in the study of CMD have understood the shortcomings of the current international

\footnotetext{
* Correspondence: abe.wassie@kcl.ac.uk

'Department of Psychiatry, School of Medicine, College of Health Sciences, Addis Ababa University, PO Box 9086, Addis Ababa, Ethiopia

${ }^{2}$ King's College London, Institute of Psychiatry, Department of Psychological Medicine, Centre for Affective Disorders, London, UK

Full list of author information is available at the end of the article
}

classification systems [3]. They argue that most nonpsychotic disorders have poorly defined boundaries and most individuals presenting to a primary care are likely to have a combination of anxiety, cognitive, depressive, somatic and vegetative complaints. Therefore, the term CMD has relevant heuristic value. But by using the term "common" to signify the common-ness of the CMDs, CMDs are often viewed as trivial and transient. Most descriptions of CMD are limited to the description of the mixed phenomenology and risk factors. Their treatment and course are not fully explored because the concept does not inform treatment to the satisfaction of clinicians. CMDs also do not fully match to the current international nosological systems of the International Classification of Diseases 
(ICD-10) [4] or the Diagnostic and Statistical Manual of Mental Disorders [5].

However, the CMD construct may be a very useful measure of the mental wellbeing of a population or a community, particularly if the assessment explores additional psychosocial risk factors that may indicate population level wellbeing and risk. CMDs can be measured easily and with minimal cost using a broad range of brief instruments that can be administered by lay interviewers with limited training. Because of the nature of categorical disorders defined by DSM and ICD systems, the level of mental disorder in a population is likely to be underestimated and, by measuring CMDs, the overall level of the psychosocial distress of a population could be evaluated more accurately resulting in an estimation closer to the actual population level morbidity. Additionally co-morbidity is less of an issue although substance related conditions are more discrete and need a separate measurement. Finally CMDs may predispose to more serious disorders although providing services may be more challenging. Therefore CMDs are likely to account for the majority of the burden of mental disorder in a population. This makes CMD of public health relevance and may be meaningful constructs to public health specialists and policy makers. CMDs should also inform treatment and attract service structuring and investment [3].

Additional population level indicators of mental distress and wellbeing may be suicidal behaviour and violence, and substance abuse. Suicidality is an important dimension of mental distress, which may be taken as an indication of the severity of a mental disorder. Suicidality may also be closely linked with impulse control, but probably mediated through various stressors and life events. Moreover, information on suicidal behaviour may not be volunteered by patients or families in low income countries because of the strong negative attitudes and shame associated with the behaviour in these settings [6-8]. Related to this negative attitude, service utilisation may be compromised. Thus, suicidal behaviour, CMD and other related psychosocial problems are important public health concerns that require further exploration. The main objective of this study was to explore the population level of burden of psychosocial problems in a rural community in Ethiopia. Specifically we aimed to determine the burden of CMD and suicidal behaviour and to assess for potential psychosocial and demographic factors associated with these outcomes.

The study was conducted as part of a situational appraisal for the Programme for Improving Mental Healthcare (PRIME) [9]. PRIME is a cross-country research consortium involving five low and middle income countries (Ethiopia, India, Nepal, South Africa and Uganda). The primary aim of PRIME is to develop evidence on the best methods of integrating mental health care into primary care. PRIME in Ethiopia will introduce broad community based interventions and facility based interventions to support integration. The current baseline survey is an important first step to understand the baseline mental health context of the community in the study setting.

\section{Methods}

The study was a cross-sectional survey of adults aged 18 years and above. The study participants were selected randomly from all sub-districts of the Sodo district proportional to the size of the population of each sub-district.

\section{Setting}

The study was conducted in the Sodo district, Gurage Zone, Southern Nations, Nationalities and Peoples Region (SNNPR), a predominantly rural district located about $100 \mathrm{~km}$ south of the capital city, Addis Ababa. The population of the district is 161,952 persons $(79,356$ men; 82,596 women) living in 58 subdistricts (kebeles) [10]. The largest ethnic group in the district is Sodo Gurage (85.3\%) followed by Oromo (11.6\%) and Amhara (1.5\%) and Amharic is the official language. The majority of the population are Orthodox Christian (97\%) with Muslims making up 2.3\%. Within Sodo district there are seven public health centres and one health centre run in a public-private partnership. There are 54 health posts (community based facilities), with another two under construction. The nearest hospital is located in Butajira town, $30 \mathrm{~km}$ South of Bui town, the capital of the district. At present there is no formal mental health care provided within the district. The nearest service is the nurse-led psychiatric unit in Butajira hospital. Sodo district was selected for this project because it is a relatively typical rural district for Ethiopia, and is located close to the research infra-structure of the Butajira research project on severe mental disorders and the Butajira Demographic Surveillance Site [11,12]. The site is also within reasonable travel distance of specialist mental health services.

\section{Participants}

Participants were consenting adults, aged 18 years and above, who had been residing in the district for at least six months. Participants were selected through systematic random sampling of households within each subdistrict and by random sampling of one adult from each selected household. The number of participants selected from each sub-district was allocated proportionate to the number of households within each sub-district. A total of 1497 participants were included in the study. This sample size was based on the assumption that the prevalence of CMD would be about $10 \%$, with a design effect of 1.5 (due to the multistage sampling of study 
participants), a precision of 0.02 and a $15 \%$ non-response. The prevalence of $10 \%$ for calculating the sample size is based on a conservative approximation of the prevalence of CMD, which ranges from about $6 \%$ to about $40 \%$ (Table 1).

\section{Assessment of CMD and psychosocial factors}

The main outcomes of interest were CMD and suicidality. Suicidality was defined as a composite of persistent death wish, suicidal ideation and suicide attempt. Assessment instruments were administered by trained community health workers with a focus on evaluating demographic status, CMD, suicidality, alcohol use disorder and psychosocial stressors. Socio-demographic assessment established basic demographic characteristics (age, sex, marital status, religion, ethnicity) and socioeconomic status (education, relative wealth and occupation). Relative wealth was assessed by simply asking the respondent what he/she perceived their wealth to be in relation to other people in the neighbourhood (poor, average or well-off)

Probable CMD was evaluated using the 10-item Kessler Psychological Distress scale (K10) [13], with three additional questions on suicidality. The K10 is a widely used

Table 1 Studies of CMD in Ethiopia over the past $\mathbf{4 0}$ years

\begin{tabular}{|c|c|c|c|c|c|c|}
\hline Reference & Location & Setting & SS & CMD measure & CMD definition & Prevalence \\
\hline \multicolumn{7}{|c|}{ First Generation studies } \\
\hline \multirow[t]{2}{*}{ [76] } & Urban & Urban health centre & 500 & Psychiatrist & CPM & $19.0 \%$ \\
\hline & Urban & Community & 100 & Psychiatrist & CPM & $8.6 \%$ \\
\hline [77] & Rural & Community & 100 & Psychiatrist & CPM & $9.0 \%$ \\
\hline \multirow[t]{2}{*}{ [78] } & Urban & General hospital clinic & 795 & Psychiatrist & CPM & $6.8 \%$ \\
\hline & Urban & Police Hospital clinic & 486 & Psychiatrist & CPM & $16.2 \%$ \\
\hline [79] & Urban & District hospital clinic & 465 & Psychiatrist & CPM & $18.3 \%$ \\
\hline \multicolumn{7}{|c|}{ Second Generation Studies } \\
\hline$[80]$ & Urban & Community & 40 & SRQ-20 & Cut-off $\geq 5$ & $12.0 \%$ \\
\hline [38] & Urban & Community (Mothers only) & 611 & SRQ-20 & Cut-off $\geq 11$ & $9.8 \%$ \\
\hline [39] & Rural & Community & 2000 & SRQ-20 & Cut-off $\geq 11$ & $11.2 \%$ \\
\hline [33] & Rural & Community & 10468 & SRQ-20 & Cut-off $\geq 11$ & $17.4 \%$ \\
\hline$[37]$ & Urban & Community & 10203 & SRQ-20 & Cut-off $\geq 6$ & $11.7 \%$ \\
\hline$[81]$ & Mixed & Community (Mothers only) & 1400 & SRQ-20 & Cut-off $\geq 8$ & $22.0 \%$ \\
\hline$[34,36]$ & Mixed & Community (Mothers only) & 1652 & SRQ-20 & Cut-off $\geq 8$ & $32.0 \%$ \\
\hline$[35]^{*}$ & Rural & Community & 902 & $\mathrm{HSCL}$ & & $42.0 \%$ in women, $37.0 \%$ in men \\
\hline [82] & Rural & Community (antenatal) & 1065 & SRQ-20 & Cut-off $\geq 5$ & $12.0 \%$ \\
\hline [1] & Rural & Community (postnatal) & 954 & SRQ-20 & Cut-off $\geq 5$ & $4.6 \%$ \\
\hline \multicolumn{7}{|c|}{ Third Generation Studies } \\
\hline \multirow[t]{4}{*}{ [41] } & Rural & Community & 501 & CIDI 1-month & Dissociative disorders & $4.5 \%$ \\
\hline & & & & & Somatoform disorders & $4.8 \%$ \\
\hline & & & & & Anxiety disorders & $2.9 \%$ \\
\hline & & & & & Depressive disorder/dysthymia & $4.9 \%$ \\
\hline \multirow[t]{2}{*}[46,47]{} & Urban & Community & 1420 & CIDI 1-month & $\begin{array}{l}\text { Dissociative, somatoform } \\
\text { or anxiety disorder }\end{array}$ & $8.1 \%$ \\
\hline & & & 1420 & CIDI 1-month & Depressive disorder/dysthymia & $3.6 \%$ \\
\hline \multirow[t]{4}{*}[42,43]{} & Rural & Community (all women) & 3016 & CIDI 12-month & Depressive disorder & $4.4 \%$ \\
\hline & & & & & Anxiety disorder & $5.7 \%$ \\
\hline & & & & & Stress-related/somatoform & $5.7 \%$ \\
\hline & & Community (married women) & 1994 & CIDI (12-month) & Depressive disorder & $4.8 \%$ \\
\hline [44] & Rural & Community & 68378 & CIDI (lifetime) & Minor depressive disorder & $2.2 \%$ \\
\hline$[45]$ & Rural Island & Community & 1714 & CIDI (lifetime) & Minor depressive disorder & 20.5 \\
\hline
\end{tabular}


tool to assess non-specific psychological distress in the past month [13]. Each item is rated from 1-5, mainly based on the persistence of a specific symptom-none of the time, a little of the time, some of the time, most of the time, and all of the time. The total score for the 10-item scale is 50 . The level of mental distress is then categorized into four groups: Those scoring 10-19 are likely to be well; those scoring 20-24 are likely to have mild mental disorder; those with a score of 25-29 are likely to have a moderate mental disorder; those scoring 30-50 are likely to have severe mental disorder [14]. A cut-off score of 19/ 20 has a sensitivity of 0.71 and a specificity of 0.90 in relation to meeting the criteria for anxiety and affective disorders according to the Composite International Diagnostic Interview [15]. Both the 10- and 6-item versions of the scale have been validated in Ethiopia among postnatal women, with the 10-item version showing superior validity [16]. We used the validated Amharic (the official language of Ethiopia) version of the K10 [16]. In this postnatal sample the sensitivity and specificity of the K10 were 0.78 and 0.84 respectively. The additional questions about suicide asked interviewees whether they had 1) experienced a death wish; 2) suicidal thoughts; and 3) attempted suicide in the previous 30 days. These three all together defined suicidal behavior.

Screening for alcohol use employed the Fast Alcohol Screening Test (FAST) derived from the Alcohol Use Disorder Identification Test (AUDIT) $[17,18]$. The FAST questionnaire has only four items and can be completed in just a minute. A total score of 3 or more confirms the occurrence of hazardous alcohol use [19], which was also what defined hazardous use in this study. The FAST has better psychometric properties than the CAGE $[20,21]$, with sensitivity of 0.93 and specificity of 0.88 [19], and comparable to the AUDIT [22]. It is also reported to have a higher sensitivity and specificity than the AUDIT when used in emergency departments [23]. Although not validated in the Ethiopian setting, the AUDIT has been used in neighbouring East African countries [24,25]. Local alcoholic beverages were converted into standard equivalent alcohol units [26].

Experience of stressful life events during the six months period prior to assessment and social support were assessed using the List of Threatening Experiences (LTE) [27] and the Oslo 3-item Social Support Scale (OSS) [28] respectively. The LTE contains 12 categories of significant life events, for example relating to death of close persons, loss of relationships, imprisonment, and being the victim of theft. These 12 categories accounted for two thirds of all events collected in the original development of the tool. The LTE has good test-retest reliability (Kappa: 0.61-0.87) and predictive validity [29]. The OSS contains three items assessing the number of close confidants, perceived level of concern from others and perceived ease of getting help from neighbours. Based on the raw scores, the scale allows a summary score (range 3-14) or categories of social support (strong, average and poor) to be generated. The OSS has good convergent and predictive validity $[30,31]$.

\section{Administration of assessment instruments}

Assessment instruments were administered by trained community health workers in Amharic, the local language of the district. These health workers were high school graduates with one year of training in health care. They were trained for two days and the instruments were piloted and pre-tested in selected sub-districts. The data collection was supervised by nurses and data supervisors with many years of experience in administering a range of mental health-related instruments.

\section{Data management and analyses}

Data were entered into Epi-data version 3.1 and analysed using the Statistical Packages for Social Sciences, version 20 (SPSS 20; IBM Corp 2012). Simple descriptive analyses were used to summarise the profile of the outcomes and factors. Logistic regression models were fitted to assess the association of the two main outcomes (CMD and suicidal behaviour evaluated one at a time) with potential risk factors. These potential risk factors were selected a priori based on evidence from existing literature and our theoretical assumption that these factors would be relevant for the outcomes of interest. Analyses of associations for CMD focused on moderate and severe disorder. Association for suicidal behaviour focused on persistent death wish, frequent suicidal ideation (occurring for at least $50 \%$ of time) and suicide attempt. Only factors that were associated with the particular outcome (CMD or suicidality) in the univariate models were included in the corresponding multivariable models in order to limit the potential risk of overadjusting without compromising identification of potential predictors for each outcome. Most of the variables were analysed as set in the original data collection tools, except for the main psychosocial factors (life events and social support). Thus experience of life events were grouped into three categories (none; $1-2$ life events and 3 and above). The total social support scores were re-categorised as per the recommended classes of poor, moderate and strong social support. Additionally, the individual social support domains were entered into the model separately. A main category of formal and informal education (those without formal schooling) were included to take into account the large number of people in Ethiopia who are literate (are able to read and write) through various educational routes, such as religious programmes and the governmental literacy programmes. 


\section{Ethical considerations}

The study was approved by the Scientific Committee of the Department of Psychiatry, Addis Ababa University, and the Institutional Review Board of the College of Health Sciences of Addis Ababa University. The conduct of the study was consistent with the Declaration of Helsinki (http://www.wma.net/en/30publications/10policies/b3/). In all cases, informed consent was sought after adequate information about the study, and the potential benefits and risks, had been provided. Participants who had significant level of depression or were suicidal were assessed by a psychiatric nurse and psychiatry residents. Whenever required, treatment was offered to these free of charge.

Table 2 Socio-demographic characteristics of participants ( $n=1497$ )

\begin{tabular}{|c|c|c|}
\hline Characteristics & & Number (\%) \\
\hline \multirow[t]{2}{*}{$\operatorname{Sex}(n=1497)$} & Male & $743(49.6)$ \\
\hline & Female & $754(50.4)$ \\
\hline \multirow{5}{*}{$\begin{array}{l}\text { Age categories (years) } \\
(n=1483)\end{array}$} & $<25$ & $226(15.2)$ \\
\hline & $25-34$ & $422(28.5)$ \\
\hline & $35-44$ & $392(26.4)$ \\
\hline & $45-59$ & $321(21.6)$ \\
\hline & $60 \&$ above & $122(8.2)$ \\
\hline Age (years) $(n=1483)$ & Mean (SD) & $37.7(13.5)$ \\
\hline \multirow[t]{3}{*}{ Marital status $(n=1484)$} & Married & $1110(74.8)$ \\
\hline & Single & $255(17.2)$ \\
\hline & Formerly married* & $75(5.1)$ \\
\hline \multirow[t]{2}{*}{ Ethnicity $(n=1490)$} & Gurage & 1409 (94.6) \\
\hline & Others** & $81(5.4)$ \\
\hline \multirow[t]{3}{*}{ Religion $(n=1441)$} & Orthodox Christian & $1327(92.1)$ \\
\hline & Protestant & $80(5.6)$ \\
\hline & Muslim & $33(2.3)$ \\
\hline \multirow[t]{3}{*}{ Education ( $n=1375$ ) } & Non-literate & $592(43.1)$ \\
\hline & $\begin{array}{l}\text { Literate but no } \\
\text { formal education }\end{array}$ & $328(23.9)$ \\
\hline & Formal education & $455(33.1)$ \\
\hline \multirow[t]{4}{*}{ Occupation $(n=1436)$} & Housewife & $404(28.1)$ \\
\hline & Farmer & $770(53.6)$ \\
\hline & Private business & $130(9.1)$ \\
\hline & Other*** & $132(9.1)$ \\
\hline \multirow[t]{2}{*}{ Residence $(n=1486)$} & Urban & $139(9.4)$ \\
\hline & Rural & $1347(90.7)$ \\
\hline \multirow{3}{*}{$\begin{array}{l}\text { Perceived relative wealth } \\
(n=1458)\end{array}$} & Poor & $498(34.2)$ \\
\hline & Average & $793(54.4)$ \\
\hline & High & 167 (11.5) \\
\hline
\end{tabular}

*Divorced/widowed/separated; **Amhara, Oromo, Tigre; ${ }^{* * *}$ Civil servant and students.

\section{Results}

Demographic characteristics

A total of 1497 people were interviewed. Most participants were from the Gurage ethnic group (94.6\%), resided in rural villages (90.7\%) and were of Orthodox Christian religion. About half (50.4\%) were women. The median age of participants was 35.0 years (interquartile range, $27.8-45.0$ ) with $8.2 \%$ aged 60 or above. Over half of the participants were either illiterate $(43.1 \%)$ or had not received any formal education although were able to read and write (23.9\%). Details are provided in Table 2.

\section{Psychosocial factors, common mental disorders and} suicidal behaviour

Major stressful life events experienced in the previous six months were common and reported by $44.7 \%$ of the interviewees. Of these $28.6 \%$ had experienced one or two life events while $16.1 \%$ had experienced three or more life events. Only $11.9 \%$ reported strong social support, while $41.8 \%$ reported poor social support (Table 3 ). Nearly half reported they were either uncertain about the concern that others show towards them or that concern from others was non-existent (49.4\%) while 55.9\% reported that they find it difficult to get help from others. The overall prevalence of probable CMD was $27.9 \%(95 \% \mathrm{CI}=25.6,30.2)$, mostly mild $(13.9 \%)$ or moderate (8.9\%) in severity; $5.0 \%$ had severe CMD (Table 2). The prevalence $(95 \% \mathrm{CI})$ of death wish, suicidal ideation, persistent suicidal ideation and actual suicide attempts, constituting suicidal behaviour in the last one-month,

Table 3 Distribution of adverse life experiences, social support and psychological distress

\begin{tabular}{|c|c|c|}
\hline \multicolumn{2}{|l|}{ Characteristics } & \multirow{2}{*}{$\frac{\text { Number (\%) }}{801(55.3)}$} \\
\hline Number of stressful & None & \\
\hline & 1 or 2 & $415(28.6)$ \\
\hline & 3 and above & $233(16.1)$ \\
\hline \multirow{3}{*}{$\begin{array}{l}\text { Social support } \\
(\mathrm{N}=1412)\end{array}$} & Poor & $590(41.8)$ \\
\hline & Moderate & $654(46.3)$ \\
\hline & Strong & $168(11.9)$ \\
\hline \multirow{4}{*}{$\begin{array}{l}\text { Common mental } \\
\text { disorder }(N=1475)\end{array}$} & Likely well & $1064(72.1)$ \\
\hline & Mild disorder & $205(13.9)$ \\
\hline & Moderate disorder & $132(8.9)$ \\
\hline & Severe disorder & $74(5.0)$ \\
\hline \multirow{2}{*}{$\begin{array}{l}\text { Hazardous use of } \\
\text { alcohol }(\mathrm{N}=1382)\end{array}$} & None & $1070(77.4)$ \\
\hline & Yes & $312(22.6)$ \\
\hline \multirow{4}{*}{$\begin{array}{l}\text { Suicidality } \\
\text { (in previous } 30 \text { days) }\end{array}$} & Wish to die $(N=1491)$ & $306(20.5)$ \\
\hline & Suicidal ideation ( $N=1497)$ & $202(13.5)$ \\
\hline & Persistent death wish $(\mathrm{N}=1444)$ & $47(3.3)$ \\
\hline & Suicide attempt $(N=1493)$ & $21(1.4)$ \\
\hline
\end{tabular}

*Also called threatening life experiences by the developers of the instrument. 
Table 4 Univariate analysis of factors associated with common mental disorder

\begin{tabular}{|c|c|c|c|c|c|c|c|c|c|}
\hline & & \multirow{2}{*}{\multicolumn{2}{|c|}{$\begin{array}{l}\text { Well or only } \\
\text { mild disorder } n \%\end{array}$}} & \multicolumn{2}{|c|}{$\begin{array}{l}\text { Moderate or } \\
\text { severe disorder } \mathrm{n} \%\end{array}$} & \multirow[t]{2}{*}{ Odds ratio } & \multicolumn{2}{|c|}{$95 \% \mathrm{Cl}$} & \multirow[t]{2}{*}{$p$ value } \\
\hline & & & & $\mathrm{N} \%$ & & & & & \\
\hline \multicolumn{10}{|l|}{ Sex } \\
\hline & Male & 631 & 49.7 & 105 & 51.0 & 1.0 & & & \\
\hline & Female & 638 & 50.3 & 101 & 49.0 & 0.96 & 0.76 & 1.20 & 0.689 \\
\hline \multicolumn{10}{|l|}{ Residence } \\
\hline & Urban & 115 & 9.1 & 22 & 10.7 & 1.0 & & & \\
\hline & Rural & 1144 & 90.9 & 184 & 89.3 & 1.19 & 0.74 & 1.93 & 0.481 \\
\hline \multirow[t]{3}{*}{ Marital status } & Single & 222 & 17.6 & 31 & 15.3 & 1.0 & & & \\
\hline & Married & 952 & 75.5 & 141 & 69.5 & 1.04 & 0.69 & 1.57 & 0.855 \\
\hline & Formerly married & 85 & 6.8 & 31 & 15.3 & 2.46 & 1.44 & 4.26 & 0.001 \\
\hline \multicolumn{10}{|l|}{ Ethnicity } \\
\hline & Gurage & 1199 & 95.0 & 190 & 92.2 & 1.0 & & & \\
\hline & Other & 63 & 5.0 & 16 & 7.8 & 0.62 & 0.35 & 1.10 & 0.105 \\
\hline \multicolumn{10}{|c|}{ Religious affiliation } \\
\hline & Orthodox & 1125 & 92.1 & 184 & 92.9 & 1.0 & & & \\
\hline & Other & 97 & 7.9 & 14 & 7.1 & 0.85 & 0.48 & 1.52 & 0.578 \\
\hline \multicolumn{10}{|l|}{ Occupation } \\
\hline & House wife & 346 & 28.5 & 54 & 26.9 & 1.0 & & & \\
\hline & Farmer & 646 & 53.2 & 114 & 56.7 & 0.91 & 0.52 & 1.60 & 0.749 \\
\hline & Private & 112 & 9.2 & 14 & 7.0 & 1.03 & 0.61 & 1.74 & 0.910 \\
\hline & Other & 111 & 9.1 & 19 & 9.5 & 0.73 & 0.35 & 1.53 & 0.404 \\
\hline \multicolumn{10}{|l|}{ Age } \\
\hline & Median (IQR) & \multicolumn{2}{|c|}{$35.0(27.8,45.0)$} & & \multicolumn{2}{|c|}{$38.0(29.1,50.0)$} & 1.01 & 1.03 & 0.002 \\
\hline \multicolumn{10}{|c|}{ Relative wealth } \\
\hline & Better off & 149 & 12.0 & 17 & 8.6 & 1.0 & & & \\
\hline & Average & 689 & 55.6 & 93 & 47.0 & 1.19 & 0.69 & 2.05 & 0.539 \\
\hline & Poor & 401 & 32.4 & 88 & 44.4 & 1.97 & 1.14 & 3.42 & 0.016 \\
\hline \multicolumn{10}{|l|}{ Education } \\
\hline & Formal education & 391 & 33.7 & 58 & 30.2 & 1.0 & & & \\
\hline & Literate but no formal education & 270 & 23.3 & 53 & 27.6 & 1.32 & 0.88 & 1.98 & 0.174 \\
\hline & Non-literate & 500 & 43.1 & 81 & 42.2 & 1.09 & 0.76 & 1.57 & 0.633 \\
\hline \multicolumn{10}{|c|}{ Mental illness in family } \\
\hline & None & 978 & 80.7 & 138 & 70.8 & 1.0 & & & \\
\hline & Yes & 234 & 19.3 & 57 & 29.2 & 1.73 & 1.23 & 2.43 & 0.002 \\
\hline \multicolumn{10}{|l|}{ Life events } \\
\hline & None & 746 & 60.8 & 48 & 23.6 & 1.0 & & & \\
\hline & $\leq 2$ events & 332 & 27.1 & 74 & 36.5 & 3.65 & 2.53 & 5.27 & $<0.001$ \\
\hline & $>2$ events & 148 & 12.1 & 81 & 39.9 & 8.25 & 5.57 & 12.22 & $<0.001$ \\
\hline \multicolumn{10}{|l|}{ Social support } \\
\hline & Strong & 152 & 12.6 & 15 & 7.9 & 1.0 & & & \\
\hline & Average & 555 & 46.2 & 88 & 46.3 & 1.65 & 0.93 & 2.94 & 0.088 \\
\hline & Poor & 495 & 41.2 & 87 & 45.8 & 1.79 & 1.00 & 3.18 & 0.048 \\
\hline
\end{tabular}


Table 4 Univariate analysis of factors associated with common mental disorder (Continued)

\begin{tabular}{|c|c|c|c|c|c|c|c|c|c|}
\hline \multicolumn{10}{|l|}{ Can count on others } \\
\hline & At least on 1 person to count on & 1164 & 86.9 & 175 & 86.2 & 1.0 & & & \\
\hline & None & 90 & 7.2 & 28 & 13.8 & 2.07 & 1.32 & 3.26 & 0.002 \\
\hline \multicolumn{10}{|l|}{ Concern from others } \\
\hline & At least some concern & 616 & 50.6 & 80 & 41.7 & 1.0 & & & \\
\hline & Little or uncertain & 601 & 49.4 & 112 & 58.3 & 1.44 & 1.05 & 1.95 & 0.022 \\
\hline \multicolumn{10}{|l|}{ Ease of help } \\
\hline & Easy & 556 & 44.1 & 77 & 37.7 & 1.0 & & & \\
\hline & Difficult & 704 & 55.9 & 127 & 62.3 & 1.30 & 0.96 & 1.77 & 0.088 \\
\hline \multicolumn{10}{|l|}{ Harmful use of alcohol } \\
\hline & None & 989 & 80.2 & 137 & 67.8 & 1.0 & & & \\
\hline & Yes & 244 & 19.8 & 65 & 32.2 & 1.92 & 1.39 & 2.67 & $<0.001$ \\
\hline
\end{tabular}

were found in $20.5 \%(18.5,22.7), 13.5 \%(11.8,15.3), 3.3 \%$ $(2.4,4.3)$ and $1.4 \%(0.9,2.1)$ respectively. About a fifth (22.4\%) reported hazardous use of alcohol, higher among men $(33.4 \%)$ compared to women $(11.3 \%)$. This difference was statistically significant: $X^{2}(1)=62.1 ; \mathrm{p}<0.001$.

\section{Factors associated with common mental disorder and suicidal behaviour}

Both univariate (Tables 4 and 5) and multivariable (Tables 6 and 7) models are presented. In the multivariable model, factors associated with CMD were increasing age $(\mathrm{OR}=1.01 ; 95 \% \mathrm{CI}=1.00,1.03 ; \mathrm{p}=0.035)$, loss of marriage $(\mathrm{OR}=2.34 ; 95 \% \mathrm{CI}=1.20,4.58 ; \mathrm{p}=0.013)$, experience of threatening life events in the previous six months $(\mathrm{OR}=1.49 ; 95 \% \mathrm{CI}=1.01,2.20 ; \mathrm{p}=0.046)$, and hazardous use of alcohol $(\mathrm{OR}=1.92 ; 95 \% \mathrm{CI}=1.39,2.67$; $\mathrm{p}<0.001$. Experiencing one or two life events increased the odds of CMD about four fold $(\mathrm{OR}=3.74 ; 95 \%$ $\mathrm{CI}=2.42,5.78 ; \mathrm{p}<0.001)$ while experiencing three or more life events doubled the odds to over eight fold $(\mathrm{OR}=8.90 ; 95 \% \mathrm{CI}=5.57,14.21 ; \mathrm{p}<0.001)$.

Marital status, lower educational status, experience of stressful life events and CMD were all associated independently with suicidal behaviour. Thus being married $(\mathrm{OR}=1.95 ; 95 \% \mathrm{CI}=1.01,3.77 ; \mathrm{p}=0.046)$, being nonliterate $(\mathrm{OR}=2.29 ; 95 \% \mathrm{CI}=1.33,3.93 ; \mathrm{p}=0.003)$ or not having formal education $(\mathrm{OR}=2.06 ; 95 \% \mathrm{CI}=1.15,3.70$; $\mathrm{p}=0.016$ ), approximately doubled the odds of exhibiting suicidal behaviour. Both life events and CMD showed an increase in odds of suicidal behaviour with increase in frequency of life events as well as increase in the severity of the CMD, as shown in Table 7.

\section{Discussion}

Indicators of high level of population level distress were found in this rural district manifested in terms of relatively high levels of CMD, suicidal behaviour, and threatening life events occurring in the context of low levels of reported social support. In relation to CMD, the prevalence found in our study is overall comparable to what has been reported in Ethiopia albeit on the higher margins. For ease of comparison, studies of CMD that have been conducted in Ethiopia are summarised in Table 1. These studies may be categorised into three generations based on the method of case detection and case definition. Case detection in the first generation studies was based on interview by psychiatrists and the studies were conducted in healthcare facilities and in small communities. The facility-based studies reported the prevalence of "conspicuous psychiatric morbidity" to be $16 \%$ to $18 \%$. The prevalence from the community-based studies was relatively low, around $6 \%$. The second generation studies used screening tools administered by lay interviewers, mainly the Self Reporting Questionnaire (SRQ) [32]. The SRQ was developed specifically for use in low and middle income countries and does not have a recommended cut-off for defining "caseness". In these studies of CMD that used the SRQ in Ethiopia, the cut-off values for caseness varied from $5 / 6$ to $11 / 12$. The prevalence of CMD varied from between 5\% to about 30\% [1,33-39]. Generally studies with lower prevalence of CMD used lower cut-offs. Although the use of such varied cut-offs makes interpretation more difficult, the use of screening tools enables larger populations to be studied. Thus two of the second generation studies evaluated over 10,000 people [33,37]. The third generation studies have used diagnostic assessments, mainly the lay intervieweradministered Composite International Diagnostic Interview [40]. These studies were able to describe the prevalence of various individual conditions that overlap with the concept of CMD (mainly anxiety disorders, depression, somatoform disorders). The prevalence of these disorders varied between $2 \%$ and $20 \%$ [41-47]. The use of a diagnostic instrument was perhaps a major step forward. 
Table 5 Univariate model of factors associated with suicidality

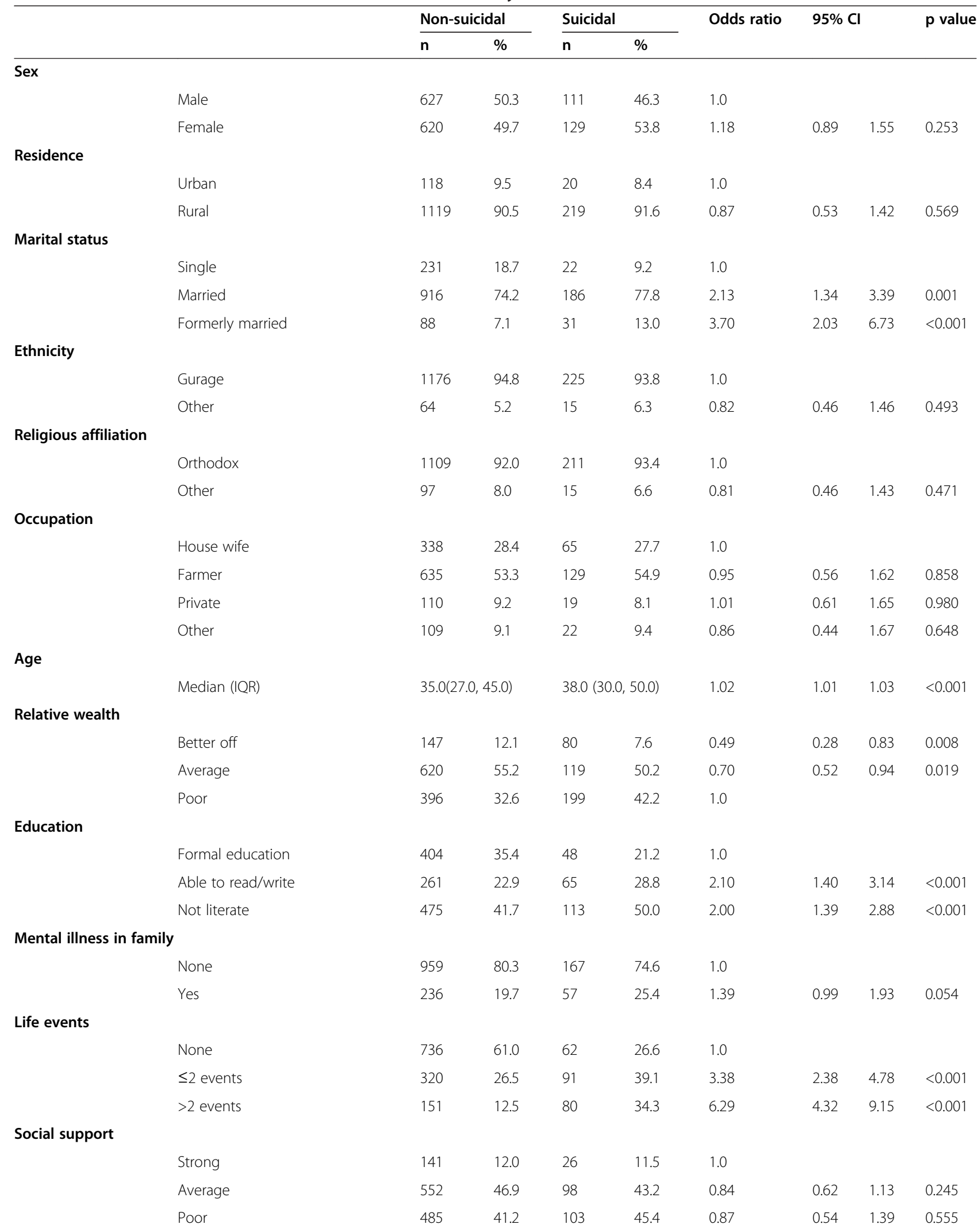


Table 5 Univariate model of factors associated with suicidality (Continued)

\begin{tabular}{|c|c|c|c|c|c|c|c|c|c|}
\hline \multicolumn{10}{|l|}{ Can count on others } \\
\hline & At least on 1 person to count on & 1138 & 92.4 & 211 & 88.7 & 1.0 & & & \\
\hline & None & 94 & 7.6 & 27 & 11.3 & 1.55 & 0.99 & 2.44 & 0.058 \\
\hline \multicolumn{10}{|l|}{ Concern from others } \\
\hline & At least some concern & 606 & 50.8 & 98 & 43.0 & 1.0 & & & \\
\hline & Little or uncertain & 587 & 49.2 & 130 & 57.0 & 1.37 & 1.03 & 1.82 & 0.031 \\
\hline \multicolumn{10}{|l|}{ Ease of help } \\
\hline & Easy & 546 & 44.1 & 90 & 38.0 & 1.0 & & & \\
\hline & Difficult & 693 & 55.9 & 147 & 56.9 & 1.29 & 0.97 & 1.71 & 0.083 \\
\hline \multicolumn{10}{|l|}{ Hazardous alcohol use } \\
\hline & None & 959 & 79.3 & 180 & 76.3 & 1.0 & & & \\
\hline
\end{tabular}

Although our study looked at the prevalence of CMD, the primary objective of our study was to make a determination of the population level mental distress for the provision of a community level intervention. In this context, our study is the only one in Ethiopia that brings together broad population level distress indicators (sucidiality and alcohol use disorder) [48] including CMD and psychosocial stressors. Within the context of CMD studies over the past 40 years, our study is also meaningful given the changes in the country in the past 15 years and the need to understand the impact of these changes on mental health. It is notable, however, that the prevalence of CMD is generally comparable to the older studies from over 15 years ago.

In the context of what is known about CMD in Ethiopia, our study indicates that CMD are relevant public health concerns. At present, the national plan for the scale up of mental health care understandably focuses on more severe disorders (psychosis, major depressive disorder and epilepsy) [49]. Our study indicates that CMD and associated suicidal behaviour are common and need to be considered in the provision of care although the approach may need to include interventions at the population level to address population level determinants.

Suicidal behaviour and psychosocial factors related to mental disorders and suicidal behaviour have not been explored in any detail in Ethiopia. Two studies looked at the lifetime prevalence of suicide attempt, which varied between $1 \%$ and $3 \%[50,51]$. For the most part the exploration of psychosocial factors was limited to sociodemographic factors. In line with previous findings, this PRIME study found lower level of education, life events and mental disorder were associated with suicidality [52-54]. The association of married status with suicidality was not in agreement with other studies, for example that of the World Mental Health Survey [54]. We did not explore the reasons for this association. However, one potential explanation is conflicts within marriage or love relations, which are reported to be common psychosocial factors identified in people attempting suicide in Africa [50,51,55,56]. Further replication of this finding and exploration of potential factors that may increase the risk of suicidal behaviour in the African context is required.

The main factors associated with CMD were psychosocial stressors (stressful life events), which was in the expected direction. Loss of a marriage was associated with CMD as reported elsewhere in Africa [57,58] as was increasing age $[57,59]$. Although low social support was associated with CMD only in the univariate model, it was associated with suicidal behaviour in the full model. Low social support is likely to be an important factor in the pathway to CMD as well as suicidality. It is of note that the finding of low social support goes against the general assumption that social support may be better in "developing" countries because of the extended family and community networks [60-62]. Of interest is that the association of relative wealth with both CMD and suicidality observed in the univariate analysis falls away in multivariable analysis, a pattern observed in relation to income in other LMICs [2]. The combination of higher level of negative life events, lower education, and low social support in conjunction with higher level of stigma [63,64], is likely to constitute a toxic milieu for the onset and maintenance of mental distress and suicidal behaviour.

The very high level of association between CMD and suicidality supports the proposal that "the reductionist model", which views suicidal behaviour in low income countries as an impulsive response to the stresses of life, is not accurate $[65,66]$. Mental disorder is likely to be an important concomitant of suicidality and should be considered in all individuals presenting with such behaviour. Furthermore, given the high association between suicidal 
Table 6 Multivariable model of factors associated with common mental disorder

\begin{tabular}{|c|c|c|c|c|c|}
\hline & & $\begin{array}{l}\text { Odds } \\
\text { ratio }\end{array}$ & & $\% \mathrm{Cl}$ & $p$ value \\
\hline Demo & tors & & & & \\
\hline Age & & 1.01 & 1.00 & 1.03 & 0.035 \\
\hline Marit & & & & & \\
\hline & Single & 1.0 & & & \\
\hline & Married & 0.99 & 0.59 & 1.64 & 0.954 \\
\hline & Formerly married & 2.34 & 1.20 & 4.58 & 0.013 \\
\hline Econo & & & & & \\
\hline Relati & & & & & \\
\hline & Better off & 1.0 & & & \\
\hline & Average & 0.76 & 0.41 & 1.41 & 0.391 \\
\hline & Poor & 1.23 & 0.66 & 2.29 & 0.524 \\
\hline
\end{tabular}

Life events

$\begin{array}{lllll}\text { None } & 1.0 & & & \\ \leq 2 \text { life events } & 3.74 & 2.42 & 5.78 & <0.001 \\ >2 \text { life events } & 8.90 & 5.57 & 14.21 & <0.001\end{array}$

Social support

$\begin{array}{lllll}\text { Strong } & 1.0 & & & \\ \text { Average } & 0.77 & 0.40 & 1.48 & 0.432 \\ \text { Poor } & 0.96 & 0.66 & 1.39 & 0.834\end{array}$

Can count

on others

$\begin{array}{lllll}\begin{array}{l}\text { At least } 1 \text { person } \\ \text { to count on }\end{array} & 1.0 & & & \\ \text { None } & 0.97 & 0.55 & 1.71 & 0.920\end{array}$

Concern from others

\begin{tabular}{llllll} 
& $\begin{array}{l}\text { At least some } \\
\text { concern } \\
\text { Little or uncertain }\end{array}$ & 1.0 & & & \\
\hline Clinical factors & & 0.95 & 1.94 & 0.092 \\
\hline
\end{tabular}

\section{Family history}

of illness

$\begin{array}{lllll}\text { No } & 1.0 & & & \\ \text { Yes } & 1.09 & 0.69 & 1.72 & 0.920\end{array}$

Harmful use of alcohol

\begin{tabular}{lllll} 
None & 1.0 & & & \\
Yes & 1.49 & 1.01 & 2.20 & 0.046 \\
\hline
\end{tabular}

behaviour and CMD, primary care staff training should include training on the assessment of psychosocial needs and the provision of care for all who present to primary care with suicidal behaviour.

Our study indicates the widespread occurrence of psychosocial stressors. Thus addressing CMD and suicidal
Table 7 Multivariable model of factors associated with suicidality

\begin{tabular}{lllll}
\hline & $\begin{array}{l}\text { Odds } \\
\text { ratio }\end{array}$ & $\mathbf{9 5 \%} \mathrm{Cl}$ & $\mathbf{p}$ value \\
\hline Demographic Factors & & & & \\
\hline Age & 1.01 & 1.00 & 1.03 & 0.142 \\
Marital status & & & & \\
\hline
\end{tabular}

$\begin{array}{lllll}\text { Single } & 1.0 & & & \\ \text { Married } & 1.95 & 1.01 & 3.77 & 0.046 \\ \text { Formerly married } & 1.42 & 0.60 & 3.39 & 0.430\end{array}$

Education

\begin{tabular}{|c|c|c|c|c|c|}
\hline & Formal education & 1.0 & & & \\
\hline & Able to read/write & 2.06 & 1.15 & 3.70 & 0.016 \\
\hline & Non-literate & 2.29 & 1.33 & 3.93 & 0.003 \\
\hline \multicolumn{6}{|c|}{ Psychosocial factors } \\
\hline \multicolumn{6}{|l|}{ Life events } \\
\hline & None & 1.0 & & & \\
\hline & $\leq 2$ life events & 2.41 & 1.53 & 3.80 & $<0.001$ \\
\hline & $>2$ life events & 2.84 & 1.67 & 4.82 & $<0.001$ \\
\hline \multicolumn{6}{|l|}{ Clinical factors } \\
\hline \multicolumn{6}{|c|}{ Family history of illness } \\
\hline & No & 1.0 & & & \\
\hline & Yes & 1.48 & 0.91 & 2.40 & 0.111 \\
\hline \multicolumn{6}{|l|}{ Severity of CMD } \\
\hline & None & 1.0 & & & \\
\hline & Mild & 6.38 & 3.97 & 10.24 & $<0.001$ \\
\hline & Moderate & 14.54 & 8.56 & 24.70 & $<0.001$ \\
\hline & Severe & 60.91 & 28.01 & 132.48 & $<0.001$ \\
\hline
\end{tabular}

$\mathrm{CMD}=$ common mental disorder

behaviour is likely to require broader programmes of psychosocial intervention. Despite the concerns about the acceptability of "talking treatments" in developing countries [67], psychosocial interventions have to be developed as part of the larger scale up plan in the country and in the context of district level programmes of intervention such as PRIME. Given the effectiveness of psychosocial interventions [68-73], improving the acceptability of talking treatments through cultural adaptation of content and delivery of interventions would be important.

\section{Limitations}

The study is cross-sectional and we cannot make inferences about causality. Although the main outcome instrument used in this study has been validated in the country, it was not validated in the local setting. However, pretesting of the instrument was carried out in this local setting. The instruments on CMD focus more on frequency of symptoms than clinical relevance (for example level of distress or disability). Although interpretation of 
the CMD syndrome identified here may appear difficult, evidence suggests that even mild disorders are associated with impairment $[74,75]$. Therefore, even if the degree of impairment was not specifically assessed, many people identified with CMD are likely to have a degree of impairment [74]. It is also to be noted that most cases of CMD have milder condition; and although the prevalence appears high, not all individuals with CMD would require treatment. Therefore, identifying individuals that are more likely to require and benefit from treatment is necessary. The analyses did not take into account fully the multistage nature of the sampling because we did not have a reliable estimate of the size of eligible household members. However, the sampling at the sub-district level was self-weighting given the sampling at the sub-district level was proportional to the number of households in the sub-districts.

\section{Conclusions}

The population level mental distress as indicated by the level of symptoms of CMD, suicidal behaviour, hazardous use of alcohol and the prevalent nature of risk factors for mental distress in the population is high $[52,53]$. The results of the study argue for the provision of population level interventions to reduce risk factors and to promote wellbeing. The results also suggest that simple psychosocial interventions applicable for this context need to be developed. Although variation in the prevalence of CMD is observed depending on methods and settings [76-82], overall, there is some consistency in the prevalence of CMD over the years.

\section{Competing interests}

The authors declare that they have no competing interests.

\section{Authors' contributions}

AF, GM, CL and CH developed the study plan. MS and MH supported data collection. AF, GM and $\mathrm{CH}$ participated in the data analysis. AF wrote the initial draft. All authors read the manuscripts, provided intellectual input and approved the final draft and submission.

\section{Acknowledgement}

This material has been funded by UK Aid from the UK Government, however the views expressed do not necessarily reflect the UK Government's official policies.

We gratefully acknowledge the support we received from the Sodo district health office, the district administration, the health extension workers who collected the data and the supervisors.

\section{Author details}

'Department of Psychiatry, School of Medicine, College of Health Sciences, Addis Ababa University, PO Box 9086, Addis Ababa, Ethiopia. ${ }^{2}$ King's College London, Institute of Psychiatry, Department of Psychological Medicine, Centre for Affective Disorders, London, UK. ${ }^{3}$ Addis Ababa University, Aklilu Lemma Institute of Pathobiology, Addis Ababa, Ethiopia. ${ }^{4}$ Federal Ministry of Health, Addis Ababa, Ethiopia. ${ }^{5}$ Alan J Flisher Centre for Public Mental Health, Department of Psychiatry and Mental Health, University of Cape Town, Cape Town, South Africa. ${ }^{6}$ King's College London, Institute of Psychiatry, Health Services and Population Research Department, London, UK.
Received: 18 January 2014 Accepted: 24 June 2014

Published: 7 July 2014

\section{References}

1. Hanlon C, Medhin G, Alem A, Araya M, Abdulahi A, Tomlinson M, Hughes M, Patel V, Dewey M, Prince M: Sociocultural practices in Ethiopia: association with onset and persistence of postnatal common mental disorders. Br J Psychiatry 2010, 197(6):468-475.

2. Lund C, Breen A, Flisher AJ, Kakuma R, Corrigall J, Joska JA, Swartz L, Patel V: Poverty and common mental disorders in low and middle income countries: A systematic review. Soc Sci Med 2010, 71:517-528.

3. Goldberg D, Goodyer I: The origins and course of common mental disorder. Sussex: Routledge; 2005.

4. World Health Organization: The International Classification of Diseases. 10th edition. Geneva: World Health Organization; 1992.

5. American Psychiatric Association: The Diagnostic and Statistical Manual of Mental Disorders. 4th edition. Washington, DC: American Psychiatric Association; 1994.

6. Alem A, Jacobsson L, Kebede D, Kullgren G: Awareness and attitude of a rural Ethiopian community toward suicidal behaviour: a community informant study in Butajira, Ethiopia. Acta Psychiatr Scand 1999, 100:65-69.

7. Mugisha J, Hjelmeland H, Kinyanda E, Knizek BL: Distancing: a traditional mechanism of dealing with suicide among the Baganda, Uganda. Transcult Psychiatry 2011, 48(5):624-642.

8. Osafo J, Hjelmeland H, Akotia CS, Knizek BL: Social injury: An interpretative phenomenological analysis of the attitudes towards suicide of lay persons in Ghana. Int J Qual Stud Health Well-being 2011, 6(4): doi:10.3402/ qhw.v3406i3404.8708.

9. Lund C, Tomlinson M, De Silva M, Fekadu A, Shidhaye R, Jordans M, Petersen I, Bhana A, Kigozi F, Prince M, Thornicroft G, Hanlon C, Kakuma R, McDaid D, Saxena S, Chisholm D, Raja S, Kippen-Wood S, Honikman S, Fairall $L$, Patel V: PRIME: A programme to reduce the treatment gap for mental disorders in five low and middle-income countries. PLoS Med 2012, 9(12):e1001359. doi:10.1371/journal.pmed.1001359.

10. Hanlon C, Luitel NP, Kathree T, Murhar V, Shrivasta S, Medhin G, Ssebunnya J, Fekadu A, Shidhaye R, Jordans M, Kigozi F, Thornicroft G, Patel V, Tomlinson M, Lund C, Breuer E, De Silva M, Prince M: Challenges and opportunities for implementing integrated mental health care: a situation analysis from five low- and middle-income country districts. PLOS One 2014, In Press.

11. Byass $P$, Berhane $Y$, Emmelin $A$, Kebede $D$, Andersson T, Högberg $U$, Wall $S$ : The role of demographic surveillance systems (DSS) in assessing the health of communities: An example from rural Ethiopia. Public Health 2002, 116(3):145-150.

12. Shamebo D, Muhe L, Sandström A, Wall S: The Butajira Rural Health Project in Ethiopia: Mortality Pattern of the Under Fives. J Trop Pediatr 1991, 37(5):254-261.

13. Kessler RC, Andrews G, LJ C, Hiripi E, Mroczek DK: Short screening scales to monitor population prevalences and trends in non-specific psychological distress. Psychol Med 2002, 32:959-976.

14. Victorian Government Department of Human Services the Health Surveillance and Evaluation Section: Victorian Population Health Survey 2001: selected findings. Victoria: Rural and Regional Health and Aged Care Services Division; 2001

15. Andrews G, Slade T: Interpreting scores on the Kessler Psychological Distress Scale (K10). Aust N Z J Public Health 2001, 25(6):494-497.

16. Tesfaye M, Hanlon C, Alem A: Detecting Postnatal Common Mental Disorders in Addis Ababa Ethiopia: Validation of the Edinburgh Postnatal Depression Scale and Kessler Scales. J Affect Disord 2010, 122:102-108.

17. Babor TF, Higgins-Biddle JC, Saunders JB, Monteir MG: The Alcohol Use Disorders Identification Test: Guidelines for Use in Primany Health Care. 2nd edition. Geneva: World Health Organization; 2001

18. Hodgson R, Alwyn T, John B, Thom B, Smith A: The FAST Alcohol Screening Test. Alcohol Alcohol 2002, 37:61-66.

19. Hodgson RJ, John B, Abbasi T, Hodgson RC, Waller S, Thom B, Newcombe RG: Fast screening for alcohol misuse. Addict behav 2003, 28(8):1453-1463.

20. Chan AW, Pristach EA, Welte JW: Detection by the CAGE of alcoholism or heavy drinking in primary care outpatients and the general population. J Subst Abuse 1994, 6(2):123-135.

21. Kelly TM, Donovan JE, Chung T, Bukstein OG, Cornelius JR: Brief screens for detecting alcohol use disorder among 18-20 year old young adults in 
emergency departments: Comparing AUDIT-C, CRAFFT, RAPS4-QF, FAST, RUFT-Cut, and DSM-IV 2-Item Scale. Addict Behav 2009, 34(8):668-674.

22. Meneses-Gaya C, Crippa JA, Zuardi AW, Loureiro SR, Hallak JE, Trzesniak C, de Sousa JP M, Chagas MH, Souza RM, Martin-Santos R: The fast alcohol screening test (FAST) is as good as the AUDIT to screen alcohol use disorders. Subst Use Misuse 2010, 45(10):1542-1557.

23. Health Development Agency: Manual for the Fast Alcohol Screening Test. London: Health Development Agency; 2002.

24. Saunders JB, Aasland OG, Babor TF, de la Fuente JR, Grant M: Development of the Alcohol Use Disorders Identification Test (AUDIT): WHO Collaborative Project on Early Detection of Persons with Harmful Alcohol Consumption-II. Addiction 1993, 88:791-804

25. Chishinga N, Kinyanda E, Weiss HA, Patel P, Ayles H, Seedat S: Validation of brief screening tools for depressive and alcohol use disorders among TB and HIV patients in primary care in Zambia. BMC Psychiatry 2011, 11:75.

26. Fekadu A, Alem A, Hanlon C: Alcohol and drug abuse in Ethiopia: past present and future. Afr J Drug Alcohol Studies 2007, 6:39-53.

27. Brugha T, Bebbington $P$, Tennant $C$, Hurry J: The List of Threatening Experiences: a subset of 12 life event categories with considerable long-term contextual threat. Psychol Med 1985, 15:189-194.

28. Dalgard OS, Dowrick C, Lehtinen V, Vazquez-Barquero JL, Casey P, Wilkinson G, Ayuso-Mateos JL, Page H, Dunn G: Negative life events, social support and gender difference in depression: a multinational community survey with data from the ODIN study. Soc Psychiatry Psychiatr Epidemiol 2006, 41(6):414-451.

29. Motrico E, Moreno-Küstner B, de Dios $\sqcup$, Torres-González F, King M, Nazareth I, Montón-Franco C, Josefa G, Gómez-Barragán M, Sánchez-Celaya M, Ángel Díaz-Barreiros M, Vicens C, Moreno-Peral P, Bellón JÁ: Psychometric properties of the List of Threatening Experiences-LTE and its association with psychosocial factors and mental disorders according to different scoring methods. J Affect Disord 2013, 150(3):931-940.

30. Boen H, Dalgard OS, Bjertness E: The importance of social support in the associations between psychological distress and somatic health problems and socio-economic factors among older adults living at home: a cross sectional study. BMC Geriatr 2012, 12:27.

31. Fekadu A, Rane L, Wooderson SC, Markopoulou K, Poon L, Cleare AJ: Prediction of longer-term outcome of treatment-resistant depression in tertiary care. Br J Psychiatry 2012, 201:369-375.

32. World Health Organization: A user's guide to the Self Reporting Questionnaire (SRQ). Geneva: Mental Health Division, World Health Organization; 1994.

33. Alem A, Kebede D, Woldesemiat G, Jacobsson L, Kullgren G: The prevalence and socio-demographic correlates of mental distress in Butajira, Ethiopia. Acta Psychiatr Scand Suppl 1999, 99(397):48-55.

34. De Silva MJ, Huttley SR, Harpham T, Kenward MG: Social capital and mental health: A comparative analysis of four low income countries. Soc Sci Med 2007, 64:5-20.

35. Hadley C, Tegegn A, Tessema F, Cowan JA, Asefa M, Galea S: Food insecurity, stressful life events and symptoms of anxiety and depression in east Africa: evidence from the Gilgel Gibe growth and development study. Epidemiol Community Health 2008, 62:980-986.

36. Harpham T, Huttly S, De Silva MJ, Abramsky T: Maternal mental health and child nutritional status in four developing countries. J Epidemiol Community Health 2005, 59:1060-1064.

37. Kebede D, Alem A, Rashid E: The prevalence and socio-demographic correlates of mental distress in Addis Ababa, Ethiopia. Acta Psychiatr Scand Supp/ 1999, 99(397):5-10.

38. Mulatu MS: Prevalence and risk factors of psychopathology in Ethiopian children. J Am Acad Child Adolesc Psychiatry 1995, 34(1):100-109.

39. Tafari $\mathrm{S}$, Aboud FE, Larson CP: Determinants of mental illness in a rural Ethiopian adult population. Soc Sci Med 1991, 32(2):197-201.

40. World Health Organization: Composite Internatinal Diagnostic Interview, version 2.1. Geneva: World Health Organization; 1997.

41. Awas M, Kebede D, Alem A: Major mental disorders in Butajira, southern Ethiopia. Acta Psychiatr Scand Supp/ 1999, 99(397):56-64.

42. Deyessa N, Berhane Y, Alem A, Ellsberg M, Emmelin M, Hogberg U, Kullgren $G$ : Intimate partner violence and depression among women in rural Ethiopia: a cross-sectional study. Clin Pract Epidemiol Ment Health 2009, 5(8): doi:10.1186/1745-0179-1185-1188.

43. Deyessa N, Berhane Y, Alem A, Hogberg U, Kullgren G: Depression among women in rural Ethiopia as related to socioeconomic factors: A community-based study on women in reproductive age groups. Scand I Public Health 2008, 36:589-597.
44. Fekadu A, Alem A, Medhin G, Shibire T, Cleare T, Prince M, Kebede D: Utility of the concept of minor depressive disorder: Evidence from a large rural community sample in a developing country setting. J Affect Disord 2007, 104:111-118.

45. Fekadu A, O'Donovan MC, Alem A, Kebede D, Church S, Johns L, Medhin G, Prince M, Shibre T: Validity of the concept of minor depression in a developing country setting. J Nerv Ment Dis 2008, 196:22-28.

46. Kebede D, Alem A: Major mental disorders in Addis Ababa, Ethiopia. III. Neurotic and somatoform disorders. Acta Psychiatr Scand Suppl 1999, 397:24-29.

47. Kebede D, Alem A: Major mental disorders in Addis Ababa, Ethiopia. II. Affective disorders. Acta Psychiatr Scand Suppl 1999, 397:18-23.

48. Kraus RF, Buffier PA: Sociocultural Stress and the American Native in Alaska: An analysis of changing patterns of psychiatric illness and alcohol abuse among Alaska Natives. Cult Med Psychiatry 1979, 3:111-151.

49. Federal Democratic Republic of Ethiopia Ministry Of Health: National Mental Health Strategy 2012/13 - 2015/16. Addis Ababa: Federal Ministry of Health; 2012.

50. Alem A, Kebede D, Jacobsson L, Kullgren G: Suicide attempts among adults in Butajira, Ethiopia. Acta Psychiatr Scand Suppl 1999, 397:70-76.

51. Kebede D, Alem A: Suicide attempts and ideation among adults in Addis Ababa, Ethiopia. Acta Psychiatr Scand Suppl 1999, 397:35-39.

52. de Menil V, Osei A, Douptcheva N, Hill AG, Yaro P, De-Graft Aikins A: Symptoms of common mental disorders and their correlates among women in Accra, Ghana: a population-based survey. Ghana Med J 2012, 46(2):95-103.

53. Patel V, Kleinman A: Poverty and common mental disorders in developing countries. Bull World Health Organ 2003, 81(8):609-615.

54. Borges G, Nock MK, Haro Abad JM, Hwang I, Sampson NA, Alonso J, Andrade LH, Angermeyer MC, Beautrais A, Bromet E, Bruffaerts R, de Girolamo G, Florescu S, Gureje O, Hu C, Karam EG, Kovess-Masfety V, Lee S, Levinson D, Medina-Mora ME, Ormel J, Posada-Villa J, Sagar R, Tomov T, Uda $H$, Williams DR, Kessler RC: Twelve-month prevalence of and risk factors for suicide attempts in the World Health Organization World Mental Health Surveys. J Clin Psychiatry 2010, 71(12):1617-1628.

55. Kinyanda $E$, Hjelmeland $H$, Musisi S: Deliberate self-harm as seen in Kampala, Uganda - a case-control study. Soc Psychiatry Psychiatr Epidemiol 2004, 39(4):318-325.

56. Ndosi NK, Waziri MC: The nature of parasuicide in Dar es Salaam Tanzania. Soc Sci Med 1997, 44(1):55-61.

57. Abiodun OA: A study of mental morbidity among primary care patients in Nigeria. Compr Psychiatry 1993, 34(1):10-13.

58. Kadri N, Agoub M, Assouab F, Tazi MA, Didouh A, Stewart R, Paes M, Toufic J, Moussaoui D: Moroccan national study on prevalence of mental disorders: a community-based epidemiological study. Acta Psychiatr Scand 2010, 121:71-74

59. Jenkins R, Njenga F, Okonji M, Kigamwa P, Baraza M, Ayuyo J, Singleton N, McManus S, Kiima D: Prevalence of common mental disorders in a rural district of Kenya, and socio-demographic risk factors. Int J Environ Res Public Health 2012, 9(5):1810-1819.

60. Isaac M, Chand P, Murthy P: Community Schizophrenia outcome measures in the wider international. Br J Psychiatry 2007, 191:S71-s77.

61. Kurihara T, Kato M, Reverger R, Tirta IGR: Eleven-year clinical outcome of schizophrenia in Bali. Acta Psychiatr Scand 2005, 112:456-462.

62. Jablensky A, Sartorius N, Ernberg G, Anker M, Korten A, Cooper JE, Day R, Bertelsen A: Schizophrenia: manifestations, incidence and course in different cultures: A World Health Organization Ten-Country Study. Psychol Med Monogr Suppl 1992, 20:1-97.

63. Assefa A, Shibre T, Asher L, Fekadu A: Internalized stigma among patients with schizophrenia in Ethiopia: a cross-sectional facility-based study. BMC Psychiatry 2012, 12:239.

64. Shibre T, Negash A, Kullgren G, Kebede D, Alem A, Fekadu A, Fekadu D, Medhin $G$, Jacobsson L: Perception of stigma among family members of individuals with schizophrenia and major affective disorders in rural Ethiopia. Soc Psychiatry Psychiatr Epidemiol 2001, 36:299-303.

65. Khan MM, Mahmud S, Karim MS, Zaman M, Prince M: Case-control study of suicide in Karachi, Pakistan. Br J Psychiatry 2008, 193:402-405.

66. Qadir F, de Silva P, Prince M, Khan M: Marital satisfaction in Pakistan: a pilot investigation. Sexual Rel Ther 2005, 20:195-209.

67. Patel $\mathrm{V}$ : The need for treatment evidence for common mental disorders in developing countries. Psychol Med 2000, 30(4):743-746. 
68. Patel V, Araya R, Chatterjee S, Chisholm D, Cohen A, De Silva M, Hosman C, McGuire H, Rojas G, Van Ommeren M: Treatment and prevention of mental disorders in low-income and middle-income countries. Lancet 2007, 370:991-1005.

69. Kitchener BA, Jorm AF: Mental health first aid training for the public: evaluation of effects on knowledge, attitudes and helping behavior. BMC Psychiatry 2002, 2(10): doi:10.1186/1471-1244X-1182-1110.

70. Patel V, Simon G, Chowdhary N, Kaaya S, Araya R: Packages of Care for Depression in Low- and Middle-Income Countries. PLOS Med 2009 6(10):e1000159.

71. Patel V, Thornicroft G: Packages of Care for Mental, Neurological, and Substance Use Disorders in Low- and Middle-Income Countries: PLoS Medicine Series. PLoS Med 2009, 6(10):e1000160.

72. Patel V, Weiss HA, Chowdhary N, Naik S, Pednekar S, Chatterjee S, Bhat B, Araya $R$, King M, Simon G, Verdeli $H$, Kirkwood B: Lay health worker led intervention for depressive and anxiety disorders in India: impact on clinical and disability outcomes over 12 months. Br J Psychiatry 2011, 199:459-466.

73. Patel V, Weiss HA, Chowdhary N, Naik S, Pednekar S, Chatterjee S, De Silva MJ, Bhat B, Araya R, King M, Simon G, Verdeli H, Kirkwood BR: Effectiveness of an intervention led by lay health counsellors for depressive and anxiety disorders in primary care in Goa, India (MANAS): a cluster randomised controlled trial. Lancet 2010, 376(9758):2086-2095.

74. Kessler RC, Berglund P, Demler O, Jin R, Merikangas KR, Walters EE: Lifetime prevalence and age-of-onset distributions of DSM-IV Disorders in the National Comorbidity Survey Replication. Arch Gen Psychiatry 2005 62:593-602

75. Rapaport MH, Judd LL: Minor depressive disorder and subsyndromal depressive symptoms: functional impairment and response to treatment. J Affect Disord 1998, 48(2-3):227-232.

76. Giel R, Van Luijk JN: Psychiatric morbidity in a small Ethiopian town. British Journal of Psychiatry 1969, 115(519):149-162.

77. Giel R, van Liujk JN: Psychiatric morbidity in a rural village in southwestern Ethiopia. Int J Soc Psychiatry 1970, 16(1):63-71.

78. Doormar M: Psychiatric illness in two contrasting Ethiopian outpatient populations. Soc Psychiatry 1974, 9:155-161.

79. Jacobsson L: Psychiatric morbidity and psychosocial background in an outpatient population of a general hospital in western Ethiopia. Acta Psychiatr Scand 1985, 71(4):417-426.

80. Kortmann F, ten Horn S: Comprehension and motivation in responses to a psychiatric screening instrument. Validity of the SRQ in Ethiopia. Br J Psychiatry 1988, 153:95-101.

81. Tadesse B, Kebede D, Tegegne T, Alem A: Childhood behavioural disorders in Ambo district, western Ethiopia. I. Prevalence estimates. Acta Psychiatr Scand Supp/ 1999, 397:92-97.

82. Hanlon C, Medhin G, Alem A, Tesfaye F, Lakew Z, Worku B, Dewey M, Araya M, Abdulahi A, Hughes M, Tomlinson M, Patel V, Prince M: Impact of antenatal common mental disorders upon perinatal outcomes in Ethiopia: the P-MaMiE population-based cohort study. Trop Med Int Health 2009, 14(2):156-166

doi:10.1186/1471-244X-14-194

Cite this article as: Fekadu et al:: Population level mental distress in rural Ethiopia. BMC Psychiatry 2014 14:194.

\section{Submit your next manuscript to BioMed Central and take full advantage of:}

- Convenient online submission

- Thorough peer review

- No space constraints or color figure charges

- Immediate publication on acceptance

- Inclusion in PubMed, CAS, Scopus and Google Scholar

- Research which is freely available for redistribution

Submit your manuscript at www.biomedcentral.com/submit
Ciomed Central 